\title{
Raul Lino, protagonista de uma mudança na arquitetura escolar durante a I República Portuguesa
}

\section{Raul Lino, the protagonist of a change in school architecture during the First Portuguese Republic}

\author{
Carlos Manique da Silva ${ }^{1}$
}

\begin{abstract}
RESUMO
O objetivo do presente artigo é o de analisar um conjunto de projetos de escolas primárias desenhados pelo arquiteto Raul Lino durante a I República Portuguesa (1910-1926). O que se procura demonstrar é que os projetos em causa afirmam uma vontade de mudança relativamente a anteriores programas arquitetónicos. Em causa, nesse momento histórico, um novo olhar sobre a criança e as realidades escolares e sociais; algo que tem implicações na maneira como a escola é fisicamente concebida. Nesse sentido, a reflexão organiza-se em torno de três entradas, que enquadram um conjunto de preocupações pedagógicas e sociais muito presentes no período histórico em questão: i) bem-estar físico e mental da criança; ii) "ensino intuitivo"; e iii) imagem social do professor de instrução primária. Por outro lado, no que concerne à análise dos espaços edificados, adota-se como matriz analítica: i) a sua forma ou estrutura morfológica; ii) a sua função e as atividades que neles se realizam; e iii) as relações existentes entre os diferentes espaços e as respetivas funções.
\end{abstract}

Palavras-chave: arquitetura escolar; Raul Lino; museus escolares; I República Portuguesa.

\footnotetext{
ABSTRACT

This paper aims to analyze a set of primary school projects designed by architect Raul Lino during the First Portuguese Republic (1910-1926). In our view, the aforementioned projects stated a willingness to change the previous

1 Universidade de Lisboa (UL), Faculdade de Psicologia e Ciências da Educação. Alameda da Universidade 1649-013, Lisboa,Portugal.
} 
architectural programs. That historic moment brought up a new conception over child development as well as over the educational and social realities, which interfered in school design. This reflection is organized around three entries that put together pedagogical and social concerns which were very present in that historical period: i) physical and mental child welfare; ii) "intuitive teaching"; iii) social image of primary school teachers. On the other hand, concerning the analysis of built spaces, we have adopted as analytical procedures: i) its shape or morphological structure; ii) its function and the activities that take place in them; iii) the relations between different spaces and respective functions.

Keywords: school architecture; Raul Lino; school museums; First Portuguese Republic.

\section{Introdução}

Há quem diga que o arquiteto que projeta um edifício escolar assume responsabilidades de pedagogo, de tal modo depende o bom ou mau funcionamento duma casa de ensino da disposição arquitetónica das suas instalações.

As palavras que acabei de citar, escritas em 1918a pelo arquiteto Raul Lino a propósito do projeto do edifício para o Liceu Central de Alves Martins, de sua autoria, remetem-nos para uma ideia: a de o edifício escolar e os seus interiores, enquanto espaços desenhados, projetarem na sua materialidade um sistema de valores (BURKE; GROSVENOR, 2008). Há, aliás, uma frase do escritor francês Noël Arnaud que sintetiza bem esse pensamento: "Je suis l'espace où je suis" (apud BACHELARD, 1970, p. 131). E, na verdade, tanto educadores como arquitetos têm considerado o edifício escolar como um agente ativo, isto é, capaz de moldar a experiência dos alunos e de veicular um determinado entendimento de educação (BURKE; GROSVENOR, 2008). Por outro lado, quando pensamos na configuração do espaço escolar como um lugar específico (FRAGO, 1993-1994) é igualmente importante ter em linha de conta a seguinte ideia: "the way a school is designed to work reflects social ideas about institutions and the education these institutions are created further" (LAWN; GROSVENOR; ROUSMANIERE, 1999, p. 75).

Nas próximas páginas analisarei um conjunto de projetos de edifícios de escolas primárias desenhados pelo arquiteto Raul Lino durante a I República Portuguesa (1910-1926). O meu objetivo é o de demonstrar que os projetos em 
causa afirmam uma vontade de mudança relativamente a anteriores programas arquitetónicos - a referência, neste caso, é o projeto-tipo da autoria de Adães Bermudes $(1898)^{2}$. Trata-se, como veremos, de uma mudança que reflete ao mesmo tempo um novo olhar sobre a criança e as realidades escolares e sociais.

No plano metodológico, a minha reflexão organizar-se-á em torno de três entradas, a saber:

i) Bem-estar físico e mental da criança - Em sintonia com a centralidade que a criança assume nas primeiras décadas do século XX, colocando-a "no centro do sistema social" (NÓVOA, 2005, p. 89), os projetos do arquiteto Raul Lino valorizam a harmonização do conjunto edificado com a paisagem natural, os ambientes com uma vertente social (p. e., cantinas escolares) e a dimensão estética dos edifícios (sobretudo no seu interior). O que está em causa, particularmente em relação a este último aspeto, é também a possibilidade de a escola participar na formação do cidadão republicano;

ii) Ensino intuitivo - A efetivação de estratégias de ensino associadas ao ensino intuitivo, conhecendo, de resto, assinalável voga nos inícios de Novecentos, tem evidentes repercussões na organização interna das escolas. É frequente, por exemplo, a especialização de um espaço pensado para museu escolar (mesmo nas escolas unitárias);

iii) Imagem social do professor de instrução primária - A valorização dessa imagem, muito fixada, como é comumente sabido, pela ideologia republicana, é percetível na importância atribuída à habitação destinada ao docente e, mesmo, na sua tipologia. Em relação a este último aspeto, os projetos incluem amiúde espaços que, do ponto de vista simbólico, revelam a intenção de mostrar uma imagem social consonante com a missão civilizadora de que o professorado estava investido (NÓVOA, 1989).

Dir-se-ia que estas três entradas enquadram um conjunto de preocupações pedagógicas e sociais muito presentes no período histórico em questão, estando, de resto, plasmadas no Decreto de 29 de março de 1911 (Reforma do ensino infantil, primário e normal), bem como nas "Normas técnicas, higiénicas e pedagógicas" que deviam orientar a construção de escolas destinadas ao ensino infantil e primário (Decreto $\mathrm{n}^{\circ} 2.947$, de 20 de janeiro de 1917). Sublinha-se, assim, que as citadas preocupações têm implicação na maneira como a escola é fisicamente concebida.

2 Para se ter uma ideia do tom crítico em relação às escolas primárias projetadas por Adães Bermudes, talvez seja suficiente dizer que, em novembro de 1912, num debate ocorrido na Câmara dos Deputados, tais edifícios foram considerados "uma verdadeira vergonha nacional" (PORTUGAL, 1912, p. 14). Na gíria, deve ainda acrescentar-se, os edifícios projetados por Adães Bermudes ficaram conhecidos por "gaiolas de grilos", clara alusão à reduzida dimensão das salas de aula. 
No que concerne à análise dos espaços edificados, adoto como matriz analítica, na linha, aliás, de autores como Thomas A. Markus (1993) e Viñao Frago (2005), os seguintes aspetos: i) a sua forma ou estrutura morfológica; ii) a sua função e as atividades que neles se realizam; e iii) as relações existentes entre os diferentes espaços e as respetivas funções.

Começo, porém, por traçar em secções autónomas, respetivamente: i) uma breve nota biográfica a respeito do arquiteto Raul Lino; e ii) a sua intervenção enquanto projetista de edifícios escolares.

\section{Raul Lino (1879-1974): breve nota biográfica ${ }^{3}$}

Raul Lino nasceu em Lisboa no ano de 1879 e nessa cidade veio a falecer em 1974. O fato de ser filho de um abastado negociante de materiais de construção deu-lhe a possibilidade de estudar no estrangeiro. Em 1890 parte para Inglaterra, frequentando um colégio católico nos arredores de Windsor. Aí permanece durante três anos, rumando depois à Alemanha com o objetivo de estudar a língua e de cursar arquitetura. Dessa experiência, Raul Lino destaca, sobretudo, os ensinamentos do professor Albrecht Haupt, em cujo ateliê trabalhou em regime de voluntariado durante dois anos.

Em 1897 está de regresso a Portugal, completando o seu curso livre de Arquitetura (o diploma oficial de arquiteto ser-lhe-á conferido em 1926) e começando a trabalhar nas oficinas do pai. Datam de finais do século XIX os primeiros trabalhos de arquitetura e as viagens pelo país, em particular pelo Alentejo, no decurso das quais recolhe diversos elementos sobre arquitetura tradicional. De resto, o projeto apresentado em 1899 para o Pavilhão de Portugal na Exposição Nacional de Paris, de 1900, afirma-se, em contraponto à influência das beaux-arts, inspirado "em estilos portugueses de várias épocas, combinados numa composição verosímil e bastante harmoniosa" (apud NÓVOA, 2003, p. 768). Numa abordagem que se prende a valores nacionais, Raul Lino procurou, aliás, encontrar uma definição de "Casa Portuguesa" que traduzisse a maneira de ser e de estar portuguesas, recuando para o efeito à matriz arquitetónica do século XVI. Linha de pensamento que influenciará decisivamente a sua obra, materializada, por exemplo, na utilização do alpendre, no recurso aos revestimentos azulejares e, mesmo, no emprego de materiais típicos de cada região. Um carácter estético

3 Esta seção é inspirada na biografia de Raul Lino inserta no Dicionário de Educadores Portugueses, obra publicada sob a direção de António Nóvoa (2003). 
particularmente visível nos projetos de moradias individuais, mas que, constatá-lo-emos a seu tempo, não deixará de estar presente nos projetos de escolas.

Autor de mais de 700 projetos arquitetónicos, Raul Lino desenvolveu a sua atividade profissional liberal em acumulação com cargos na administração pública, designadamente na Direção-Geral dos Edifícios e Monumentos Nacionais. Entre as suas obras de referência contam-se a Casa dos Patudos (Alpiarça, 1904), a Casa do Cipreste (Sintra, 1912), o cinema Tivoli (Lisboa, 1925) e o Pavilhão do Brasil na Exposição do Mundo Português (1940).

Curiosamente, ao longo da vida, Raul Lino foi também desenvolvendo áreas como a azulejaria, os vitrais e o mobiliário, revelando assim uma grande versatilidade e a vontade de integrar a arte em todas as manifestações da vida humana. Foi ainda autor de estudos teóricos como A Casa Portuguesa (1929), Casas Portuguesas (1933) e L'Évolution de l'architecture domestique au Portugal (1937).

\section{Raul Lino, "arquiteto da escola"}

Os primeiros projetos de edifícios escolares da autoria de Raul Lino nasceram da amizade que travou com João de Deus Ramos ${ }^{4}$. De fato, numa parceria muito estreita: ao primeiro coube a conceção arquitetónica; ao segundo as bases pedagógicas de um dos primeiros jardins-escolas construídos em Portugal (inaugurado na cidade de Coimbra em abril de 1911) ${ }^{5}$. Até meados dos anos de 1960, o arquiteto continuaria a desenhar projetos de jardins-escolas basicamente segundo o mesmo modelo, neles se incluindo o de Lisboa, construído com o Museu João de Deus e inaugurado em 1915.

Para além do projeto matricial dos jardins-escolas João de Deus, que mereceu nota muito positiva a um observador atento como João de Barros (1920), importa dizer que, durante a I República, Raul Lino teve intensa atividade como projetista de edifícios escolares. Por outras palavras, a sua ação no campo da arquitetura escolar não deve ficar unicamente balizada pelos citados projetos de jardins-escolas e pelos projetos-tipo regionalizados para edifícios de escolas primárias, por si igualmente desenhados e aprovados em 1935 por Duarte

4 João de Deus Ramos era filho do poeta e pedagogo João de Deus, autor da Cartilha Maternal.

5 Importa notar que a educação infantil foi um dos desideratos da República, consagrada, aliás, na Reforma do ensino infantil, primário e normal de 1911 (PORTUGAL, 1911). 
Pacheco, então ministro das Obras Públicas: uma visão que a historiografia não tem ajudado a desvanecer. E, para o efeito, bastaria enunciar, tomando como referência o período de tempo correspondente à I República, os seguintes projetos, sendo que nem todos tiveram tradução prática: escola primária para Alcântara (1916); escolas primárias-tipo (1918); Liceu Central de Alves Martins (1918); escola primária no concelho de Esposende (1919); escola agrícola em Coimbra (1921); escola agrícola feminina em Alcobaça (1922); escola primária com habitação para o professor no concelho da Figueira da Foz (1922) 6 . Por outro lado, importa de igual modo referir que, em 1921, Raul Lino desenhou vários tipos de regionalizados de habitações para professores, aos quais, de resto, dedicarei mais tarde algumas linhas ${ }^{7}$.

\section{"Apurar o gosto pela estética, desenvolver o culto pelo belo, incutir o amor da natureza"}

A partir da década de 1860, num momento histórico em que ganham visibilidade diversas propostas tendentes a promover a frequência do ensino elementar (instituição de cursos noturnos, fomento de inspeção às escolas, criação de cursos normais...), o tema dos edifícios escolares entra decisivamente no debate pedagógico (NÓVOA, 1987; SILVA, 2002). É então veiculada uma ideia-chave: a da inconsequência da obrigatoriedade do ensino primário sem a existência de edifícios escolares que reunissem condições pedagógicas e higiénicas ( $c f$., por exemplo, GHIRA, 1864) ${ }^{8}$. Sublinhe-se que esta afirmação está muito vinculada a pressupostos higienistas, se quisermos, a uma nova ética, bem sintetizada na expressão "enfermer pour décrasser" (CSERGO, 1988, p. 89). E se a ideia é igualmente tornar a escola atrativa, mas simples, no sentido de chamar a si as camadas mais pobres e desvalidas da sociedade (precisamente as que, aos olhos da elite cultural, constituíam o fim da escola pública), não

${ }^{6}$ Os citados projetos fazem parte do espólio de Raul Lino, depositado na Fundação Calouste Gulbenkian. Encontram-se todos disponíveis online através do site da Fundação (FCG, 2013). No entanto, não incluem as memórias descritivas.

7 Lino (1921).

8 Note-se que nos anos de 1860 (e, mesmo, alguns decénios mais tarde), o panorama dos edifícios escolares é verdadeiramente calamitoso. Para se ter uma ideia, em 1913, estimava-se serem necessários 8953 edifícios para o ensino elementar, sendo que, nessa data, existiam apenas 287 erigidos segundo o plano "conde de Ferreira" e 100 segundo o de "Adães Bermudes"; os restantes apresentavam-se em precárias condições ( $c f$. FONSECA, 1913). 
menos importante será dizer que a estética dos edifícios escolares está longe de ser uma questão essencial (muito menos a educação estética das crianças). Do meu ponto de vista, essa preocupação aflora justamente durante a I República, e não apenas pela mão de pedagogos. Paradigmático, a esse respeito, é o repto lançado pelo escritor Afonso Lopes Vieira, em 1913, num artigo publicado na revista Educação e significativamente intitulado "Escolas belas ou morrer?". Outros relatos, porém, denunciam o panorama desolador das escolas portuguesas, enfatizando ao mesmo tempo (particularmente pelo contraponto que estabelecem) a importância da estética e, mesmo, do belo nas edificações escolares. Atente-se no seguinte exemplo:

Encerrar as crianças em salas como aquela que eu frequentei, onde a luz e o ar entravam a medo por uma única janela e em que a estética eram umas paredes negras como o azeviche, e o adorno, velhas teias de aranha, é o mesmo que metê-las em enxovias, embotar-lhes o gosto pelo belo, criar-lhes o desamor pela instrução (FONSECA, 1913, p. 19).

Um ano depois, uma das conclusões do congresso pedagógico promovido pelo Sindicato dos Professores Primários de Portugal centrava-se exatamente nessa temática:

[É necessário] fazer uma intensa propaganda da decoração interna e externa das escolas, por meio de estampas escolhidas e flores criando assim um ambiente de arte e beleza, em que a criança se desenvolverá, educando o seu sentimento estético (CONGRESSO PEDAGÓGICO, 1914, p. 11-12).

Durante a I República, Raul Lino será um dos arquitetos que mais atenção prestará à temática da decoração das escolas, procurando, e as palavras são suas, emprestar-lhes uma "nota de brandura" (LINO, 1918a, p. 21). Uma imagem que, para melhor ser compreendida, pressupõe que continuemos a acompanhar a memória descritiva do Liceu Central de Alves Martins:

Trabalhei por dar ao projetado edifício um aspeto de propriedade e de interesse artístico. Adotei fórmulas o mais económicas possível, e por 
meio da proporção, da variedade e dos contrastes, procurei evitar a uniformidade e a monotonia em que tão facilmente se pode cair quando se trata de edificações desta ordem. Aborreço [sic] o aspeto indiferente de escolas que se assemelham a grandes edifícios industriais (LINO, 1918a, p. 20).

E a essa luz preconiza a inclusão de

tanto uns pequenos jardins como principalmente algumas árvores que se deviam deixar desenvolver a todo o seu grande porte, pelo menos a meio de cada um dos recreios, e que com a sua ramaria muito fariam por suavizar a rigidez dos grandes telhados (LINO, 1918a, p. 20).

A importância que o arquiteto atribui à decoração dos edifícios escolares e, mesmo, à sua harmonização na paisagem natural, fica, porém, sobretudo expressa nos projetos de escolas primárias. Note-se que, em 1912, no âmbito de uma campanha promovida por Afonso Lopes Vieira em prol da educação das crianças portuguesas, Raul Lino é convidado a desenhar um projeto destinado a uma escola primária. A referida campanha, intitulada "As nossas crianças" e divulgada nas páginas do jornal A Capital (VIEIRA, 1912), defendia, entre outras medidas mais ou menos radicais, a inutilização de todas as escolas do Estado (NOBRE, 2012). Em sua substituição, porém,

construir-se-iam, empregando os materiais próprios de cada região, outras tantas e muitas mais escolas do tão lindo tipo indicado na gravura, desenho inédito, original do arquiteto Raul Lino. Construídas, seria preciso decorá-las, florindo-as e pondo nas suas paredes, em vez de mapas gordurosos, pendurados nos pregos ferrugentos, a alegria dos cromos e dos frisos, preparando assim as gerações futuras para a maior alegria que um bom latino pode gozar - a admiração - e para que venham a tratar com menos selvajaria do que seus maiores as paisagens e as coisas belas da sua grei (apud NOBRE, 2012, p. 4).

A referida gravura denuncia a inserção do edifício escolar num ambiente bucólico, ostentando na parede exterior um painel de azulejos representando Luís Vaz de Camões ( $c f$. VIEIRA, 1912). O que me parece sobretudo interes- 
sante realçar é que Raul Lino vai procurar plasmar nos seus projetos as ideias defendidas por personalidades como João de Deus Ramos e Afonso Lopes Vieira, as quais, aliás, estavam em linha com as suas próprias convicções. O intento era então o de formar através da escola, conforme se expressava na Reforma do ensino, infantil, primário e normal, "a alma da pátria republicana" (PORTUGAL, 1911). Ora, esse desiderato passava, como enaltecia João de Barros a propósito do Jardim-Escola de Coimbra, pela existência de "uma atmosfera absolutamente nacional", excluindo-se "todo e qualquer vestígio do estrangeiro, quer na construção e arranjo da casa, quer nas decorações, quer no método de ensino" (BARROS, 1920, p. 25). Alguns anos antes, João de Barros exaltara igualmente a ação de Raul Lino nesse mesmo sentido, o de "ter uma sensibilidade bem portuguesa que nunca o deixa fazer obra que não seja nacional" (LINO, 1916a, p. 331).

Paradigmático em relação a tudo aquilo que temos vindo a focar é o projeto da Escola Primária de Alcântara (Lisboa), desenhado por Raul Lino em $1915^{9}$. Na verdade, trata-se de um projeto totalmente em oposição àquilo que existia nas construções escolares portuguesas; o próprio arquiteto considera-o o "menos incompleto" da sua produção (LINO, 1916a, p. 335). O edifício, esse, foi inaugurado em 1916, destinando-se (e faço notar que ainda hoje se mantém em funcionamento) a 800 crianças de ambos os géneros. Na implantação da Escola, o arquiteto, numa nota que sublima o contato com a natureza, opta por desvalorizar o "eixo da rua camarária que lhe dá acesso", manifestando, em vez disso, "o maior respeito pelo sol que a ilumina e pelas boas velhas oliveiras que a engrinaldam" (LINO, 1916a, p. 335).

Por outro lado, denotando uma preocupação de ordem estética, indica que procurou fugir "àquela fisionomia antipática em que é fácil cair-se, dada a uniformidade obrigada dos vãos de janela e quando o orçamento é exíguo, e que pode fazer lembrar as casas de trabalhos forçados" (LINO, 1916a, p. 335). De resto, é assaz curiosa a conotação que Raul Lino atribui a alguns aspetos decorativos do interior do edifício:

Uma ingénua decoração enxaquetada de azulejo chama a atenção do enxame estudioso para a entrada do seu cortiço, e esta em si é formada por um largo e baixo arco, feito menos para impor respeito às crianças do que para engolir sofregamente o turbilhão gargalhante de rapazes e raparigas (LINO, 1916a, p. 335). Alcântara.

9 Cabe dizer que partiu do Estado a iniciativa para a construção da Escola Primária de 


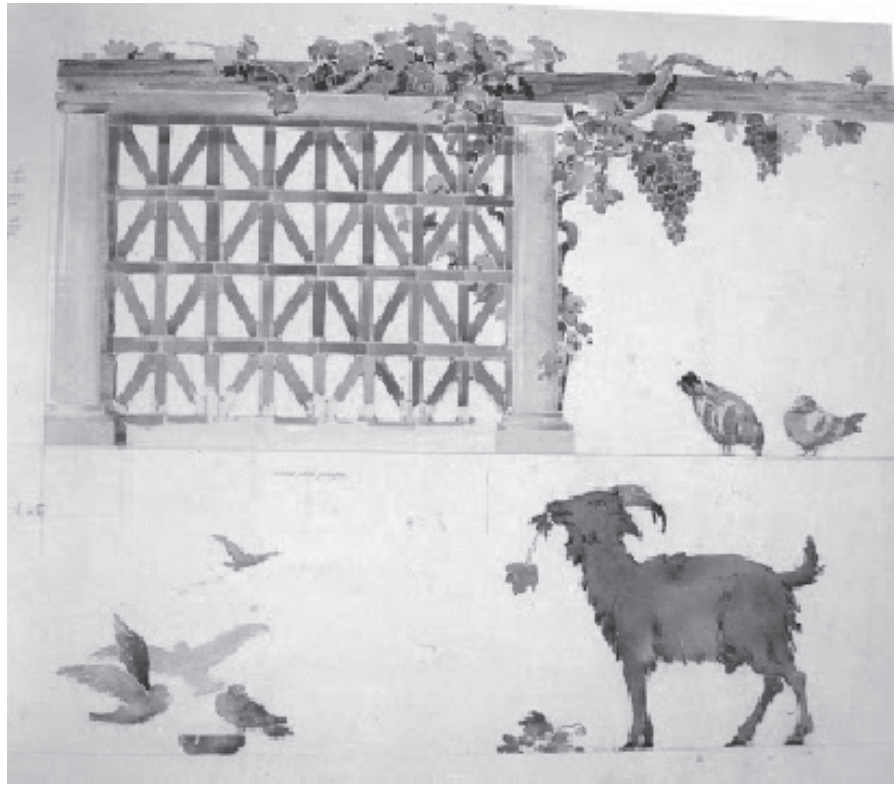

FIGURA 1 - PROJETO DE REVESTIMENTO AZULEJAR PARAA ESCOLA PRIMÁRIA DE ALCÂNTARA, DA AUTORIA DE RAUL LINO.

FONTE: Leite (1990).

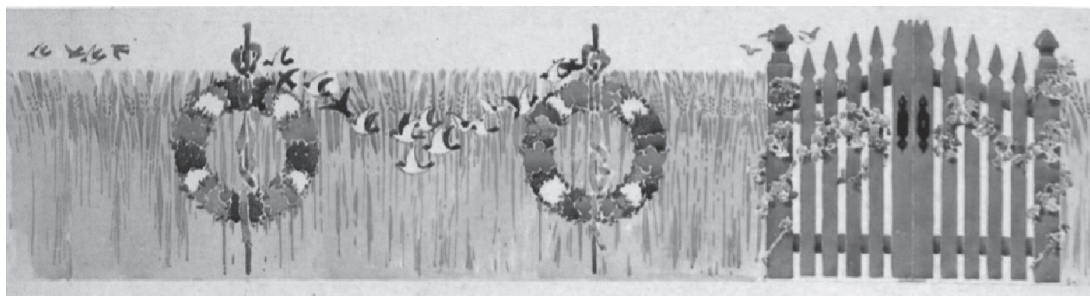

FIGURA 2 - PROJETO DE REVESTIMENTO AZULEJAR PARA A ESCOLA PRIMÁRIA DE ALCÂNTARA, DA AUTORIA DE RAUL LINO.

FONTE: Leite (1990).

O programa de decoração do interior do edifício, para além de sublimar a cultura e a tradição nacionais e de fazer a apologia da natureza - note-se que Raul Lino apelará ao nacionalismo na arte, sendo, a esse respeito, paradigmática a já citada questão da "Casa Portuguesa" -, elucida-nos bem quanto à intenção do arquiteto conferir uma nota ridente ao ambiente educativo (lembre-se, a propósito, a sua expressão "o turbilhão gargalhante de rapazes e raparigas"). 

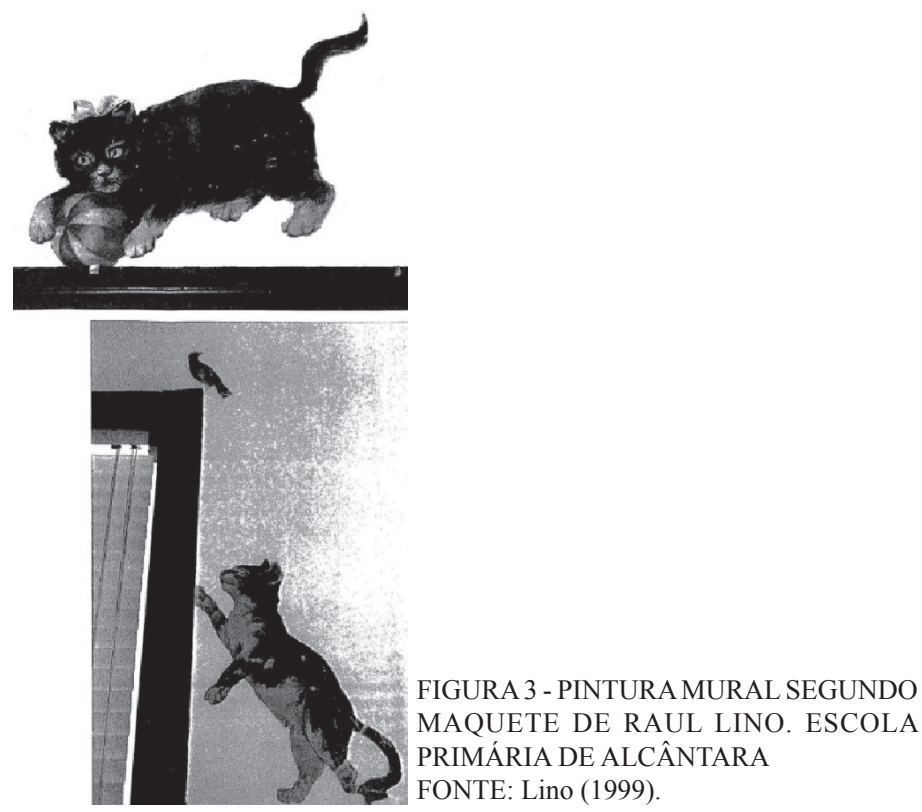

Raul Lino procura assim criar um ambiente educativo aprazível, alegre, de algum modo libertador para a criança, atribuindo também, como já se disse, particular destaque ao espaço envolvente da escola ${ }^{10}$. Esta perspetiva, que enfatiza no fundo a preocupação com o bem-estar mental e físico da criança, terá significativa expressão, na década de 1920, nos Estados Unidos da América e no Reino Unido (BURKE; GROSVENOR, 2008).

Há um outro assunto, de natureza eminentemente social, que assume especial importância para o arquiteto; traduz-se na inclusão de uma cantina escolar, à qual, como refere, dá "uma disposição mais carinhosa como sendo naturalmente a casa querida dos pequenos", projetando-a "em polígono aberto por todos os lados sobre o campo de recreio assombreado por um soberbo plátano" (LINO, 1916a, p. 335). Ora, a leitura da planta do piso térreo deixa perceber o destaque conferido à cantina, confirmado, na verdade, pelas suas dimensões (e pelo fato de esse espaço ser única e exclusivamente pensado para esse fim).

10 Há uma evidente diferença entre a importância atribuída ao contato com a natureza por razões higienistas, o mesmo é dizer, à valorização do ar e da luz na educação das crianças, e a apologia que é feita da natureza no sentido da ligação simbólica ao campo, muito presente na decoração do interior do edifício. 


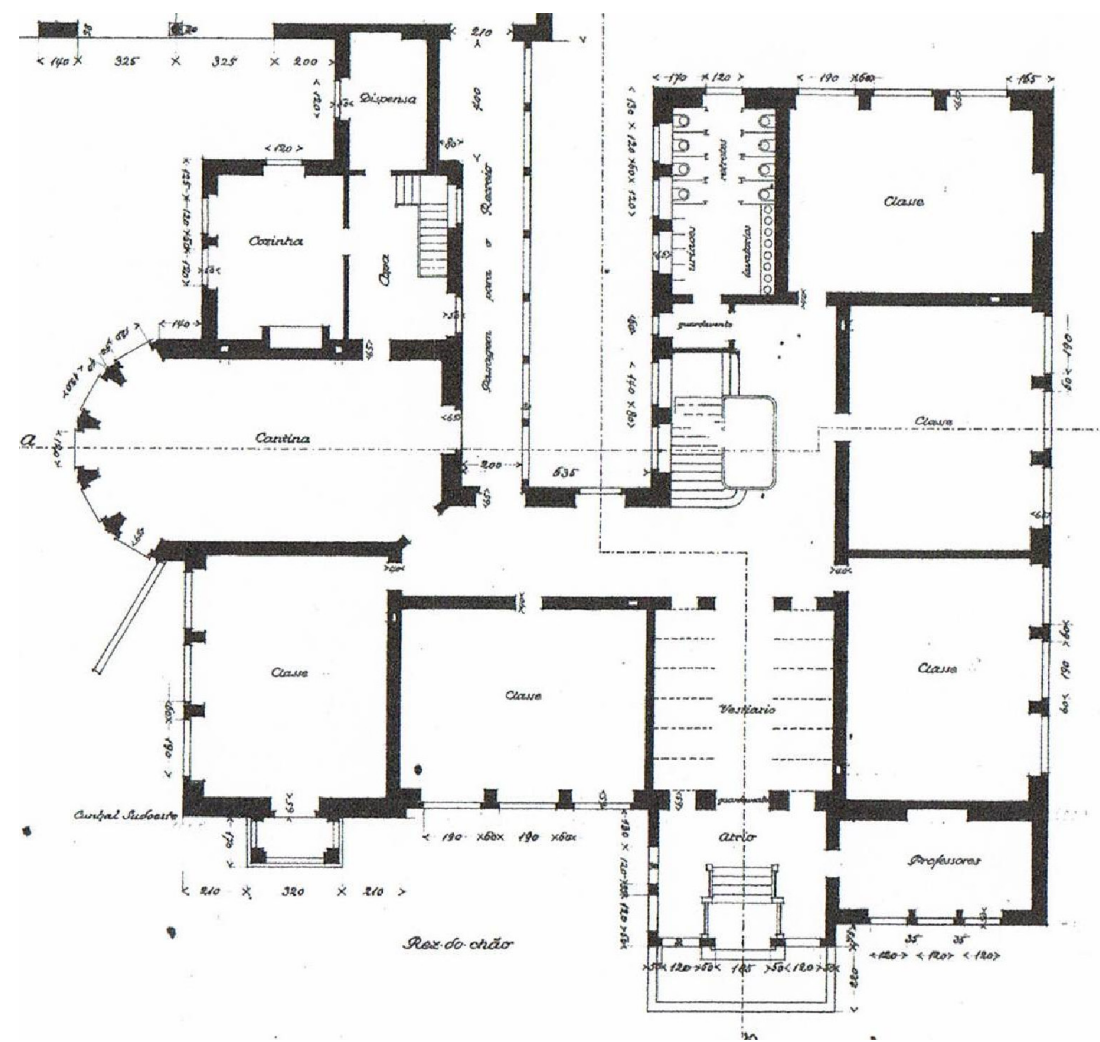

FIGURA 4 - PROJETO DA ESCOLA PRIMÁRIA DE ALCÂNTARA, PLANTA DO PISO TÉRREO, RAUL LINO, 1915

FONTE: Lino (1915).

Em síntese, os projetos de Raul Lino desenhados durante a I República, em particular o da Escola de Alcântara, refletem bem o papel atribuído à escola (no caso, à arquitetura escolar) na formação do cidadão. O culto pelo belo, o contato com a natureza e uma educação assente no arreigado amor à pátria são alguns dos "valores" presentes nos seus projetos. Não menos importante será dizer que o arquiteto protagoniza uma importante mudança na concepção da arquitetura escolar, integrando as novas ideias sobre higiene e pedagogia difundidas na Europa durante a primeira década do século XX (BURKE; GROSVENOR, 2008). 


\section{A especialização de espaços para o "ensino intuitivo"}

O “ensino intuitivo" está presente no texto da Reforma do ensino infantil, primário e normal de 1911. De fato, lê-se no diploma reformista: "todo o ensino primário deve ser essencialmente prático, utilitário e quanto possível intuitivo" (PORTUGAL, 1911). É certo que o "ensino intuitivo" e as chamadas "lições de coisas" se mantiveram como uma das grandes modas pedagógicas entre as décadas finais do século XIX e as décadas iniciais do século seguinte (PINTASSILGO, 2012). Não surpreende, assim, que as citadas "Normas técnicas, higiénicas e pedagógicas" (PORTUGAL, 1917) estabeleçam a existência de museus escolares nos edifícios destinados a escolas primárias. Ora, esses espaços são pensados com uma vocação eminentemente presentista. Quer dizer, o objetivo é o de servirem de auxiliar aos estudos e contribuírem para a modernização educativa e não, propriamente, numa perspetiva memorialista, para a salvaguarda dos recursos educativos (PEÑA SAAVEDRA; FUSTES, 2005). No fundo, o que estava em agenda era "dispensar-se o mais possível o livro" e de serem "obrigatórias as lições de coisas" (PORTUGAL, 1911).

Os projetos desenhados por Raul Lino fazem, exatamente, eco dessa orientação do ensino, obedecendo, de resto, às prescrições contidas nas citadas "Normas técnicas, higiénicas e pedagógicas" $"$. Note-se que a existência de um museu escolar está prevista mesmo no caso das escolas unitárias. Todavia, por razões que se prendem essencialmente com a exiguidade do espaço, tal função é partilhada, ou seja, o gabinete do docente serve também "para museu, biblioteca e observações médico-pedagógicas" (PORTUGAL, 1917, cap. II) ${ }^{12}$. A função em causa, porém, torna-se mais explícita nos projetos de escolas graduadas. Analisemos o seguinte exemplo.

11 É importante referir que estas "Normas", apresentadas com caráter provisório, haviam sido publicadas pela Imprensa Nacional no ano de 1914.

12 A este respeito, veja-se, por exemplo, o projeto de escola unitária desenhado por Raul Lino no ano de 1918 ( $c f$. LINO, 1918b). 


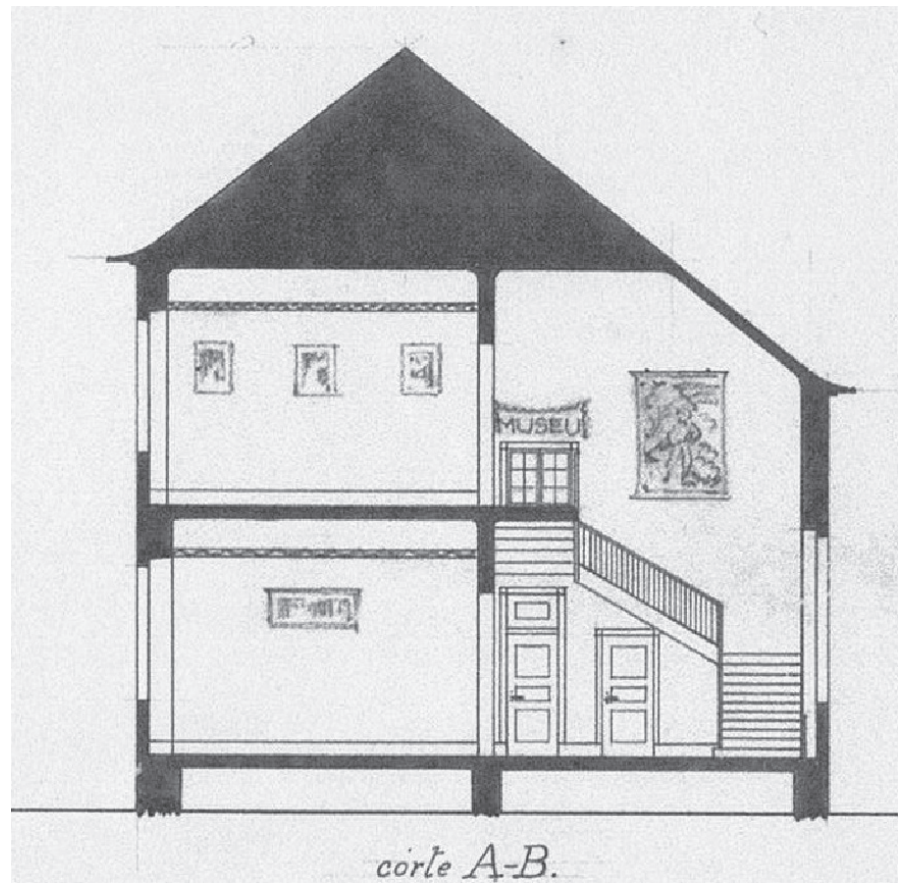

FIGURA 5 - CORTE TRANSVERSAL DE UM MODELO DE ESCOLA GRADUADA, RAUL LINO, 1916

FONTE: Lino (1916b).
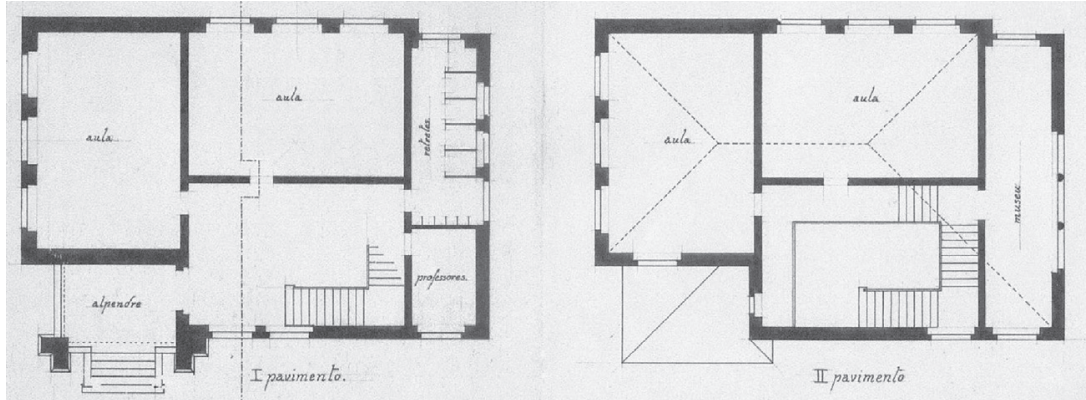

FIGURA 6 - PLANTAS DE UM MODELO DE ESCOLA PRIMÁRIA GRADUADA, RAUL LINO, 1916

FONTE: Lino (1916b). 
Do ponto de vista da especialização do espaço, verificamos que, para além de quatro salas de aula (duas em cada piso), o modelo incluía um gabinete ou sala para os professores e um lugar destinado a museu (desconheço, no entanto, se eram exclusivamente reservados a esse fim) ${ }^{13}$. Em relação ao primeiro, compreende-se a sua localização no piso térreo, junto à escadaria de acesso ao andar superior. Efetivamente, trata-se de o local onde melhor se podia controlar a passagem de alunos. Além do mais, a presença do gabinete dos professores no piso térreo, dando diretamente para o átrio, indicia uma relação de proximidade com determinados coletivos (familiares dos alunos, inspeção...). Por outro lado, as dimensões do museu expressam bem a importância concedida ao "ensino intuitivo". A valorização desse espaço é tanto mais evidente pelo fato de inexistirem ambientes especializados para outras funções. Surpreende, por exemplo, a ausência de um ginásio ou de uma sala para trabalhos manuais, disciplinas previstas no desenho curricular estabelecido no citado Decreto de 29 de março de 1911. Por fim, em termos de localização, importa considerar a proximidade do museu do gabinete dos professores. De fato, ainda que em pisos diferentes, ambos estão situados nas extremidades da escadaria. Ora, no meu entender tal distribuição sublinha uma ligação: a responsabilidade atribuída ao conselho escolar de organizar e administrar o museu ${ }^{14}$.

Raul Lino desenhou outros projetos de escolas graduadas que concediam particular destaque ao museu escolar. Penso, designadamente, no referenciado projeto da Escola Primária de Alcântara. Mas o que importa sobretudo assinalar é que a intenção de criar espaços para o "ensino intuitivo" traduz bem o esforço republicano no sentido de aproximar o sistema escolar português do dos outros países europeus.

\section{A valorização da habitação destinada aos docentes}

Até a um momento histórico bem recente, dir-se-ia meados do século XX, a dicotomia casa do mestre/escola influenciou decisivamente a organização interna dos edifícios projetados para o ensino primário. Note-se, aliás, que a própria expressão "casa da escola", consagrada na literatura pedagógica de Oitocentos,

13 É muito provável que o espaço onde estava previsto instalar o museu escolar fosse unicamente destinado a essa função, tanto mais que é claramente identificado com uma legenda.

14 Regulamento da criação e funcionamento dos conselhos de professores nas escolas primárias centrais (i. e., graduadas), publicado em 24/2/1910 (PORTUGAL, 1910). 
sugere a dupla imagem de alojamento para o professor e de salas organizadas para receber os alunos às horas das lições (CAMPAGNE, 1886). É justamente a partir dessa perspetiva que um autor como Manuel Brullet (1998) introduz o conceito de domesticidade, no fundo para explicar o processo de transformação de um espaço doméstico num espaço especificamente pensado e desenhado para o ensino. A essa luz se entende que, na casa do professor, a sala destinada às aulas, em resultado de novas necessidades qualitativas e quantitativas, vá progressivamente tornar-se independente e agregar outros espaços.

Alguns projetos de Raul Lino denunciam essa dicotomia. Quer dizer, incluem habitação para o docente no edifício escolar, sendo, aliás, elevada a permeabilidade entre as duas esferas. Ora, este último aspeto é negativamente considerado nas "Normas técnicas, higiénicas e pedagógicas", advertindo-se, em consequência, que entre a "residência [do professor] e a escola não poderá haver qualquer comunicação interior" (PORTUGAL, 1917, cap. I). Percebe-se, no entanto, à luz da mesma regulamentação, que a habitação do docente é bastante valorizada, em particular nos meios rurais:

Constará [a habitação do docente], pelo menos, de seis divisões: gabinete de estudo, sala de jantar, três quartos, cozinha [...] e terá contíguo um pequeno quintal inteiramente separado das outras dependências da escola (PORTUGAL, 1917, cap. I).

O modelo de escola primária que a seguir se reproduz elucida-nos, entre outros aspetos, quanto ao problema da delimitação entre serviço público e atividade privada.

Verifica-se que o arquiteto reserva um espaço muito generoso (e diferenciado do ponto de vista das funções) para a habitação do docente, sublinhando, dessa forma, a relevância social da missão do professorado. Por outro lado, contrariando as "Normas técnicas, higiénicas e pedagógicas" (recorde-se, publicadas pela primeira vez em 1914 embora apresentadas sempre com caráter provisório), opta por permitir a ligação interior entre a escola e o ambiente doméstico. Julgo que esta decisão se prende com a necessidade de garantir a afirmação do professor junto das populações, identificando-se de forma inextricável com a escola; esta, no fundo, não é mais do que a projeção do seu lar (a ideia que está aqui presente é a de haver uma profunda entrega à profissão).

A intenção de valorizar a imagem social do professor de instrução primária fica particularmente expressa nos projetos que Raul Lino desenhou para habitações destinadas a docentes (neste caso, moradias isoladas). Tudo leva a crer 


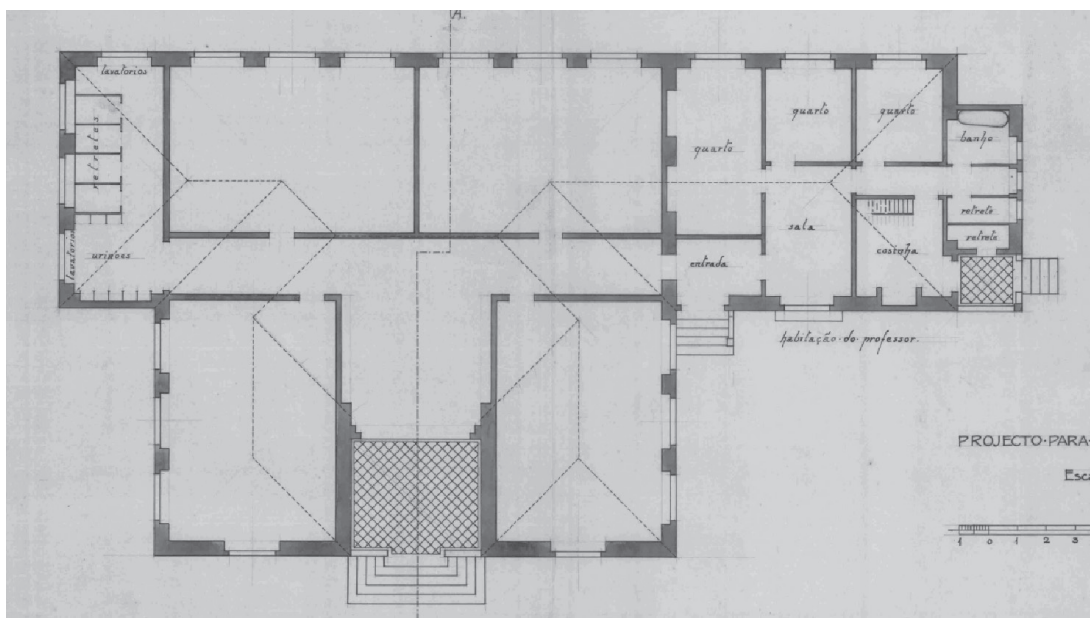

FIGURA 7 - PLANTADO PISO TÉRREO DE UM MODELO DE ESCOLA PRIMÁRIA COM HABITAÇÃO PARA O DOCENTE, RAUL LINO, 1916

FONTE: Lino (1916b).

tratar-se de uma encomenda da parte do Estado, no ano de 1921 (porém, sem concretização prática). O objetivo era o de facultar aos docentes uma habitação (dir-se-ia, muito condigna), sendo, ademais, previstos vários modelos-tipo consoantes às regiões do país. Para se ter uma ideia da imagem que se pretendia transmitir do professor de instrução primária, basta dizer que as habitações em causa incluíam um escritório e um quarto destinado à criada ${ }^{15}$.

\section{Concluindo}

Este artigo procurou reconhecer a influência que o arquiteto Raul Lino teve, num determinado período histórico, na conceção de edifícios escolares. Talvez pelas ligações que estabeleceu com personalidades ligadas ao campo educativo (nomeadamente João de Deus Ramos), Raul Lino interpretou e plasmou nos seus projetos um conjunto de ideias, em voga durante a segunda década do século $\mathrm{XX}$, acerca do desenvolvimento da criança, do ensino e da aprendizagem. Nesse sentido, os edifícios que projetou - e, diga-se, todos os edifícios escolares - são, 
para parafrasear Burke e Grosvenor (2008, p. 11), "views about how teachers and learners in designed spaces should be supported to act, and to what end". Com efeito, a "leitura" dos projetos de Raul Lino denuncia, de modo essencial, duas coisas: i) a vontade de criar um ambiente escolar que permitisse à criança envolver-se no estudo de uma forma alegre (marcando uma importante rutura com anteriores projetos); e ii) a intenção de descentrar a atividade pedagógica da sala de aula (seja através da valorização dos espaços envolventes da escola, seja, igualmente, através da especialização de espaços para o "ensino intuitivo").

É evidente, por outro lado, que no referido período histórico a arquitetura escolar é entendida como um importante fator de mudança, designadamente no que concerne à formação do cidadão republicano e, mesmo, na projeção de uma determinada imagem do professor de instrução primária.

\section{REFERÊNCIAS}

BACHELARD, Gaston. La poétique de l'espace. Paris: PUF, 1970.

BARROS, João de. A república e a escola. Lisboa: Aillaud Bertrand, 1920.

BRULLET, Manuel. L'arquitectura dels espais educatius. Temps d'Educació, Barcelona, n. 19, p. 23-33, 1998.

BURKE, Catherine; GROSVENOR, Ian. School. London: Reaktion Books, 2008.

CAMPAGNE, E. M. Dicionário universal de educação e ensino. Porto: Livraria Internacional de Ernesto Chardron, 1886.

CONGRESSO PEDAGÓGICO, 1., 1914, Porto. Conclusões aprovadas e votos emitidos. Porto: Tipografia A. F. Vasconcelos, 1914.

CSERGO, Julia. Liberté, egalité, propreté. La morale de l'hygiène au XIXe siècle. Paris: Éditions Albin Michel, 1988.

FONSECA, Tiago dos Santos. O problema da obrigatoriedade do ensino primário e a frequência das escolas. Revista de Educação Geral e Técnica, Lisboa, n. 1, p. 17-25, jan. 1913.

FRAGO, Antonio Viñao. Del espacio escolar y laescuela como lugar: propuestas e cuestiones. Historia de la Educación, Madrid: Sociedad Española de Historia de la Educación, n. 12-13, p. 17-74, 1993-94.

. Espaços, usos e funções: a localização e disposição física da direção escolar na escola graduada. In: BENCOSTTA, Marcus Levy Albino (Org.). História da educação, arquitetura e espaço escolar. São Paulo: Cortez, 2005. p. 15-47. 
FUNDAÇÃO CALOUSTE GULBEKIAN (FCG). Espólio Raul Lino. Disponível em: $<$ http://www.biblarte.gulbenkian.pt/index.php?headline $=72 \&$ visual $=1 \&$ langId $=1>$. Acesso em: 13/8/2013.

GHIRA, Mariano. Casas para escholas. Archivo Pittoresco, Lisboa: Typographia de Castro Irmão, n. 7, p. 207-208, 1864.

LAWN, Martin; GROSVENOR, Ian; ROUSMANIERE, Kate (Eds.). Silences and images: the social history of classroom. New York: Peter Lang, 1999.

LEITE, António Maria Pinto (Coord.). Raul Lino: artes decorativas. Lisboa: Fundação Ricardo Espírito Santo, 1990.

LINO, Maria do Carmo de V. e Sousa. As artes decorativas na obra de Raul Lino. Tese (Mestrado em História da Arte) - Universidade Lusíada, Lisboa, 1999.

LINO, Raul. Projecto de Escola Primária para Alcântara para ser construída na Tapada da Ajuda, Lisboa. Espólio Raul Lino 1902-1974, 1915. 3 desenhos de arquitetura. Disponível em: $<$ http://www.biblartepac.gulbenkian.pt/ipac20/ipac.jsp?session=13BX41420A677.2 8151\&profile $=$ ba\&source $=\sim$ ! fogga\&view $=$ subscriptionsummary \&uri $=$ full $=3100024 \sim$ ! 192806 !2\&ri=5\&aspect=basic_search\&menu=search\&ipp=20\&spp $=20 \&$ staffonly $=\&$ term=ESCOLA+PRIM $\%$ C3\%81RIA+raul+lino\&index=.GW\&uindex=\&aspect=basic search\&menu=search\&ri=5>. Acesso em: 13/8/2013.

. Edifícios escolares até 1916. Espólio Raul Lino, 1916b. 7 desenhos de arquitetura. Disponível em: <http://www.biblartepac.gulbenkian.pt/ipac20/ipac.jsp?session=E3K64 1736898Y.28181\&profile $=$ ba\&source $=\sim$ ! fcgbga\&view $=$ subscriptionsummary\&uri $=$ ful $\mathrm{l}=3100024 \sim$ ! 188083 $+4 \& \mathrm{ri}=9 \&$ aspect $=$ subtab62\&menu $=$ search\&ipp $=20 \& \mathrm{spp}=20 \&$ sta ffonly $=\&$ term $=$ raul + lino\&index $=. \mathrm{GW} \&$ uindex $=\&$ aspect $=$ subtab62\&menu $=$ search $\&$ ri $=$ 9\&ultype $=$ PD01\&uloper $==\& u l l i m i t=1916>$. Acesso em: 13/8/2013.

$1916 \mathrm{a}$.

. Edifícios Escolares de Raul Lino. Atlântida, Portugal e Brasil, n. 4, p. 332-336,

. Escolas Primárias, modelo 1, tipo norte, centro e sul. Espólio Raul Lino 19021974, 1918b. Disponível em: <http:/www.biblartepac.gulbenkian.pt/ipac20/ipac.jsp?se ssion $=13764$ S605081C. 28169 \&profile $=$ ba \&source $=\sim$ ! fcgbga\&view $=$ subscriptionsumm ary \&uri $=$ full $=3100024 \sim$ ! 188231 $~ ! 0 \&$ ri $=4 \&$ aspect $=$ subtab63\&menu=tab13\&ipp=20\&s $\mathrm{pp}=20 \&$ staffonly $=\&$ term $=$ escola + Raul + Lino $+1918 \&$ index $=. G W \& u$ index $=\&$ aspect $=$ su btab63\&menu=search\&ri=4>. Acesso em: 13/8/2013.

. Projeto do Edificio para o Liceu Central de Alves Martins Viseu. Memória Descritiva. Lisboa: Imprensa Libânio da Silva, 1918a.

. Casas de habitação para professores tipo central, serrano, ribatejano, norte e queluz. Espólio Raul Lino 1902-1974, 1921. 5 desenhos de arquitetura. Disponível em: $<$ http://www.biblartepac.gulbenkian.pt/ipac20/ipac.jsp?session=13G641M990309.281 $17 \&$ menu $=$ search\&aspect $=$ basic_search $\& n p p=20 \&$ ipp $=20 \&$ spp $=20 \&$ profile $=$ ba $\&$ ri $=\&$ 
index $=$. TW \&term $=$ Casas + de + habita $\% \mathrm{C} 3 \% \mathrm{~A} 7 \% \mathrm{C} 3 \% \mathrm{~A} 3 \mathrm{o}+$ para + professores $\& \mathrm{x}=6 \& \mathrm{y}=$ 13\&aspect=basic_search $>$. Acesso em: 13/8/2013.

MARKUS, Thomas A. Buildings and power. Freedom and control in the origin of modern building types. Londres, Nova Iorque: Routledge, 1993.

NOBRE, Cristina. Um século sobre o projeto de Afonso Lopes Vieira para as crianças e as escolas portuguesas. In: CONGRESSO LUSO-BRASILEIRO DE HISTÓRIA DA EDUCAÇÃO, 9., 2012, Lisboa. Atas... Lisboa, 2012.

NÓVOA, António. Le temps des professeurs. Lisboa: INIC, 1987.

. A República e a escola: das intenções generosas ao desengano das realidades. In: PORTUGAL. Reformas do ensino em Portugal. Reforma de 1911. Lisboa: I.I.E., 1989. p. IX-XXXIV.

(Dir.). Dicionário de educadores portugueses. Porto: Asa, 2003.

. Evidentemente. Porto: Asa, 2005.

PEÑA SAAVEDRA, Vicente; FUSTES, Emilio Castro. Les Musées Pédagogiques dans le Monde Ibérique. Rétrospective et Actualité. In: INTERNATIONAL SYMPOSIUM FOR SCHOOL MUSEUMS AND SCHOOL HISTORICAL, 11., 2005, Cidade. Anais... Suíça, 2005.

PINTASSILGO, Joaquim. Reformismo republicano e inovação pedagógica: a difusão do "ensino intuitivo". In: ADÃO, Áurea; SILVA, Carlos Manique da; PINTASSILGO, Joaquim (Orgs.). O Homem vale, sobretudo, pela educação que possui. Revisitando a primeira reforma republicana do ensino infantil, primário e normal. Lisboa: Instituto de Educação da Universidade de Lisboa, 2012. p. 81-95.

PORTUGAL. Diário de Governo, Lisboa, n. 45, 28 fev. 1910.

. Decreto de 29 de março de 1911. Diário do Governo, Lisboa, n. 73, 30 mar. 1911. . Diário da Câmara dos Deputados, Lisboa, 13 nov. 1912. Disponível em: $<\mathrm{http}: / /$ debates.parlamento.pt/catalog.aspx?cid=r1.cd>. Acesso em: 13/8/2013.

. Decreto $\mathrm{n}^{\circ} 2.947$, de 20 de janeiro de 1917. Diário do Governo, Lisboa, n. 11, $1^{\mathrm{a}}$ série, 20 jan. 1917.

SILVA, Carlos Manique da. Escolas belas ou espaços sãos? Uma análise histórica sobre a arquitetura escolar portuguesa (1860-1920). Lisboa: IIE, 2002.

VIEIRA, Afonso Lopes. As nossas crianças. A Capital, Lisboa, p. 1, 4 fev. 1912.

Texto recebido em 10 de dezembro de 2012.

Texto aprovado em 19 de agosto de 2013. 